\title{
Automated Storm Tracking and the Lightning Jump Algorithm Using GOES-R Geostationary Lightning Mapper (GLM) Proxy Data
}

\author{
ELISE V. SCHULTZ \\ University of Alabama in Huntsville, Huntsville, Alabama \\ CHRISTOPHER J. SCHULTZ \\ NASA/MSFC, Huntsville, Alabama \\ LAWRENCE D. CAREY \\ University of Alabama in Huntsville, Huntsville, Alabama \\ DANIEL J. CECIL \\ NASA/MSFC, Huntsville, Alabama \\ MONTE BATEMAN \\ USRA, Huntsville, Alabama
}

(Manuscript received 29 July 2015; review completed 31 May 2016)

\begin{abstract}
This study develops a fully automated lightning jump system encompassing objective storm tracking, Geostationary Lightning Mapper proxy data, and the lightning jump algorithm (LJA)—which are important elements in the transition of the LJA concept from a research to an operational-based algorithm. Storm cluster tracking is based on a product created from the combination of a radar parameter (vertically integrated liquid) and lightning information (flash rate density). Evaluations show that the spatial scale of tracked features or storm clusters has a large impact on the lightning jump system performance, where increasing spatial scale results in a decreased dynamic range of the system's performance. This framework also serves as a means to refine the LJA itself to enhance its operational applicability. Parameters within the system are isolated and the system's performance is evaluated with adjustments to parameter sensitivity. The system's performance is evaluated using the probability of detection and false alarm ratio statistics. Of the algorithm parameters tested, the sigma-level (i.e., a metric of lightning jump strength) and flash rate threshold influence the system's performance the most. Finally, minor changes in verification methods can dramatically impact the evaluation of the lightning jump system.
\end{abstract}

\section{Introduction}

Previous research has shown that rapid increases in lightning activity (i.e., lightning jumps) are highly correlated with the occurrence of severe weather (Williams et al. 1999; Schultz et al. 2009, hereafter S09; Gatlin and Goodman 2010) — using lightning data from available three-dimensional lightning networks throughout the United States. Furthermore, recent studies (S09; Gatlin and Goodman 2010; Schultz et al. 2011, hereafter S11) have quantified the lightning jump based on statistical performance metrics, including probability of detection (POD) and false alarm ratio (FAR). S09 and S11 presented strong performance results (i.e., 79\% POD, 36\% FAR) using total lightning from lightning mapping arrays (LMAs) to aid in the prediction of severe and hazardous weather using an objective lightning jump algorithm (LJA) with semi-automated tracking on a large number of storms. S09 developed and tested four different LJA 
configurations and determined that the $2 \sigma$ algorithm (sigma-level of 2; see section 2c of S11) had the best skill in nowcasting severe weather potential.

S09, S11, and others lack full automation and semi-objective tracking techniques that are needed for operational usage of the LJA. In addition, these previous studies have not taken advantage of adding satellite-based products to that of commonly used radar-based products. Rudlosky and Fuelberg (2013) used objective tracking techniques, but also lacked full automation. Chronis et al. (2015) also used objective and automatic tracking techniques (using real-time datasets) to understand how performance metrics change for the lightning jump. However, all of these studies arrived at their conclusions from LMA datasets and did not account for, or anticipate, what the Geostationary Lightning Mapper (GLM) will observe once in orbit on the Geostationary Operational Environmental Satellite (GOES)-R (Goodman et al. 2013). Proch (2010) is the only previous study to use the LMA-derived GLM proxy data. Proch (2010) used storms from the S09 database to evaluate the LJA with GLM proxy data. Proch's (2010) results showed that a lower sigma-level and lower flash rate threshold might be needed to optimize the algorithm for severe weather detection with GLM proxy data.

In light of the above, the goal of this study is to develop a fully automated framework-encompassing objective tracking, GLM proxy lightning data, and the LJA - to build toward operational assessment of storm intensity in real-time. This framework also will serve as a means to refine the LJA itself to enhance its operational applicability. This paper will describe the methods involved with establishing this fully automated system and discuss how adjustments to parameters within various parts of the system affect the overall performance. In section 2, we describe the components of the lightning jump system and illustrate the automated, objective tracking method-including how this differs from past research that solely relied on radar information for tracking. The components of the LJA are described, including the parameters involved in sensitivity testing. Finally, verification methods are addressed as an additional way of assessing the system's performance. Section 3 examines the sensitivity tests performed and the influence that individual and combined parameters had on the LJA system. Section 4 summarizes the key influences on the system's performance and looks forward to future research and considerations.

\section{Data and methods}

The lightning jump system consists of three components: radar and lightning data, thunderstorm tracking, and the LJA. Each component plays a vital role in the automation of the LJA towards operational use. The database for this study includes $>90$ event days consisting of up to $1000^{1}$ storm clusters between the years 2002 and 2011, and within $125 \mathrm{~km}$ of the North Alabama Lightning Mapping Array (NALMA) network center (Fig. 1; Table 1). This dataset is a significant subset of the event days included in S11. Storm clusters are included in the database if they have a minimum lifetime of $>30 \mathrm{~min}$ while the cluster is within $125 \mathrm{~km}$ of the center of NALMA. Only the portion of the cluster track that is within the domain is included in the dataset. Unlike previous studies that subjectively selected storms on each event day to include in the database, this study includes all identified storms that meet the tracking criteria as identified by the tracking method discussed in section $2 b$.

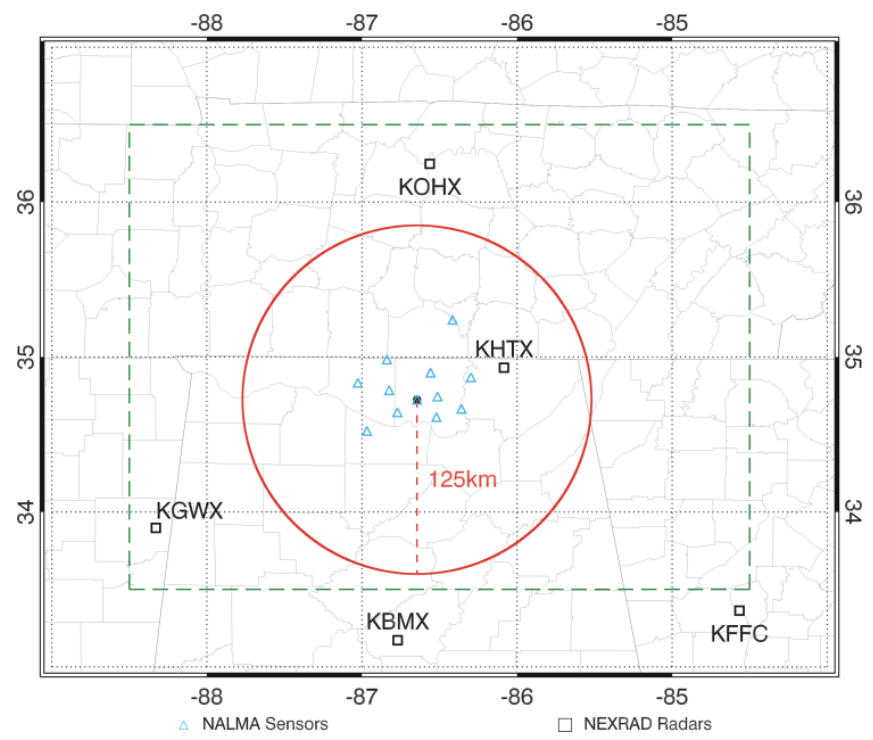

Figure 1. A diagram of the study's domain and instrumentation locations. The large rectangle (green dashed lines) indicates the domain used in the WDSS-II storm tracking algorithms. The red circle indicates the area within $125 \mathrm{~km}$ of the center of the NALMA; this is the area used for lightning jump system sensitivity testing and verification. The blue triangles represent NALMA sensors and the black boxes represented NEXRAD radar locations. Click image for an external version; this applies to all figures hereafter.

1 The number of storm clusters is dependent upon the tracked feature size. 
Table 1. Comparison of the tunable parameters in the LJA, verification, and database used in S11 and this study.

\begin{tabular}{|c|c|c|}
\hline Tunable Parameter & S11 & This study \\
\hline $\begin{array}{c}\text { Sigma-level threshold } \\
\text { (i.e., statistical jump } \\
\text { threshold) }\end{array}$ & 2.0 & $\begin{array}{c}0.75,1.0,1.25, \\
1.5,1.75,2.0, \\
2.25,2.5\end{array}$ \\
\hline $\begin{array}{c}\text { Minimum flash rate } \\
\text { (flashes min }{ }^{-1} \text { ) required } \\
\text { to activate the algorithm }\end{array}$ & 10 & $1,5,10,15,20$ \\
\hline $\begin{array}{c}\text { Minimum algorithm spin- } \\
\text { up time required to } \\
\text { determine a jump }\end{array}$ & 14 min & 14 min \\
\hline $\begin{array}{c}\text { Storm report distance } \\
\text { beyond the cell boundary }\end{array}$ & 0 km (i.e., only the \\
\hline $\begin{array}{c}\text { Verification time- } \\
\text { window following a jump }\end{array}$ & 45 min $^{\text {Dithe cell) }}$ & $5 \mathrm{~km}$ \\
\hline $\begin{array}{c}\text { Domain range from } \\
\text { NALMA center }\end{array}$ & $200 \mathrm{~km}(\mathrm{most}$ were \\
within $150 \mathrm{~km})$ & $125 \mathrm{~km}$ \\
\hline $\begin{array}{c}\text { Spatial scale based on } \\
\text { WDSS-II tracking } \\
\text { parameters }\end{array}$ & $60 \mathrm{~km}^{2}$ & See Table 2 \\
\hline
\end{tabular}

\section{a. Radar and lightning data}

\section{1) RADAR}

For each event day, Next-Generation Radar (NEXRAD) level II radar data for the five radars (KHTX, KGWX, KOHX, KFFC, KBMX; see Fig. 1) closest to the NALMA center are merged and gridded $\left(0.009^{\circ} \times\right.$ $0.009^{\circ} \times 1-\mathrm{km}$ grid boxes, Fig. 2 b) using the Warning Decision Support System-Integrated Information (WDSS-II, Lakshmanan et al. 2006, 2007). Whereas previous studies used reflectivity-based thresholds for thunderstorm tracking $\left(35 \mathrm{dBZ}\right.$ at $\left.-15^{\circ} \mathrm{C}, \mathrm{S} 09\right)$, this study uses vertically integrated liquid (VIL) in combination with lightning data. VIL is calculated from the merged and gridded radar data following the same method for single radar quality control and multi-radar blending as the national Multi-Radar Multi-Sensor system at the National Centers for Environmental Prediction, and provided to the National Weather Service (NWS) in real-time (Smith et al. 2016).

\section{2) LIGHTNING DATA: GLM PROXY DATA}

Previous implementations of the LJA involved ground-based datasets that used three-dimensional LMA data and have not included observations from a satellite-based sensor. The challenge is that an optical lightning detection instrument does not currently exist at geostationary orbit. Furthermore, optical instruments like the GLM observe a different component of lightning than the LMA [optical radiances at cloud top versus very high frequency (VHF) observations]. This study uses GLM proxy data generated from NALMA data (Bateman 2013). The GLM proxy data convert NALMA flashes into a "best guess" of what GLM will see when in orbit. The GLM proxy dataset accomplishes this by using flash statistics collected from the space-borne Lightning Imager Sensor (LIS) onboard the Tropical Rainfall Measuring Mission (TRMM; Kummerow et al. 1998) and the NALMA (Bateman et al. 2008). Like the GLM, the LIS records optical events that are grouped into flashes (Mach et al. 2007), whereas the LMA detects VHF electromagnetic radiation sources that are combined into flashes using a separate clustering algorithm (McCaul et al. 2009). An example of a visual comparison for a flash between the LIS and LMA is shown in Fig. 3. Essentially, the GLM proxy flashes are transformed to match the lower spatial resolution of the GLM (compared with NALMA). This causes some "smearing out" and some merging of NALMA flashes, but the overall flash rate is basically unchanged. The GLM proxy data algorithm creates "proxy pixels" and the flashclustering software converts these into "proxy flashes." Using this intercomparison method, the GLM proxy flashes are composed of merged LMA $15 \%$ of the time. In other words, there are roughly $15 \%$ fewer GLM proxy flashes than LMA flashes. Each GLM proxy flash location is determined by the amplitudeweighted centroid of the groups/events. GLM proxy flashes are gridded to a $0.08^{\circ} \times 0.08^{\circ}$ grid that approximates GLM resolution; and 1- and 5-min flash count total grids (FLCT1 and FLCT5) are calculated each minute to produce flash rate density (FRD) products.

\section{3) VILFRD}

This study extends beyond traditional utilization of radar parameters to track storm features, and combines lightning data with VIL to compute a new, trackable quantity. VIL and the 5-min average GLM proxy FRD (FLCT5; Fig. 2a) products are combined to track storm clusters within the WDSS-II framework. These products are combined as seen in the equation below to produce a new product, aptly named, VILFRD (Fig. 2c)

$$
\operatorname{VILFRD}=100 \times\left[\left(\frac{V I L}{45} \leq 1\right)+\left(\sqrt{\frac{F L C T 5}{45}} \leq 1\right)\right]
$$



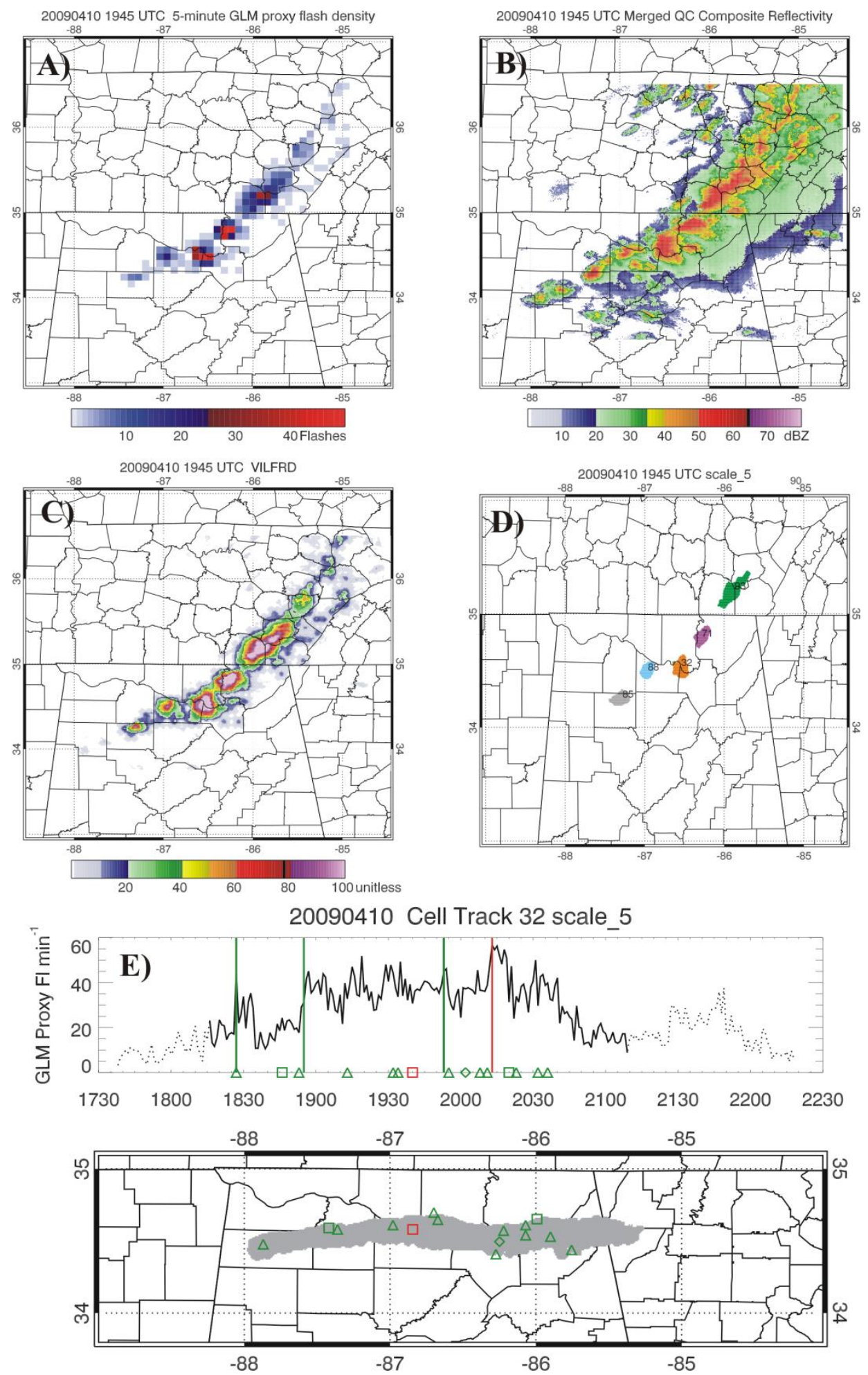

Figure 2. a) 5-min GLM proxy gridded flash density, b) merged composite reflectivity, c) VILFRD, and d) tracked storm clusters at scale 5 at 1945 UTC 10 April 2009. e) Top panel: lightning flash rate time series for cell 32 with the timing of lightning jumps depicted by green (hit) and red (false alarm) vertical lines; the light gray flash rate (i.e., 1730-1815 and 2120-2230) depicts the time the cluster is outside of the 125-km LMA range. Bottom panel: cluster footprint with storm reports (green $=$ hit, red $=$ miss) for the LJA from 1730 to 2230. Triangles are hail reports, squares are wind reports, and diamonds are tornado reports. 


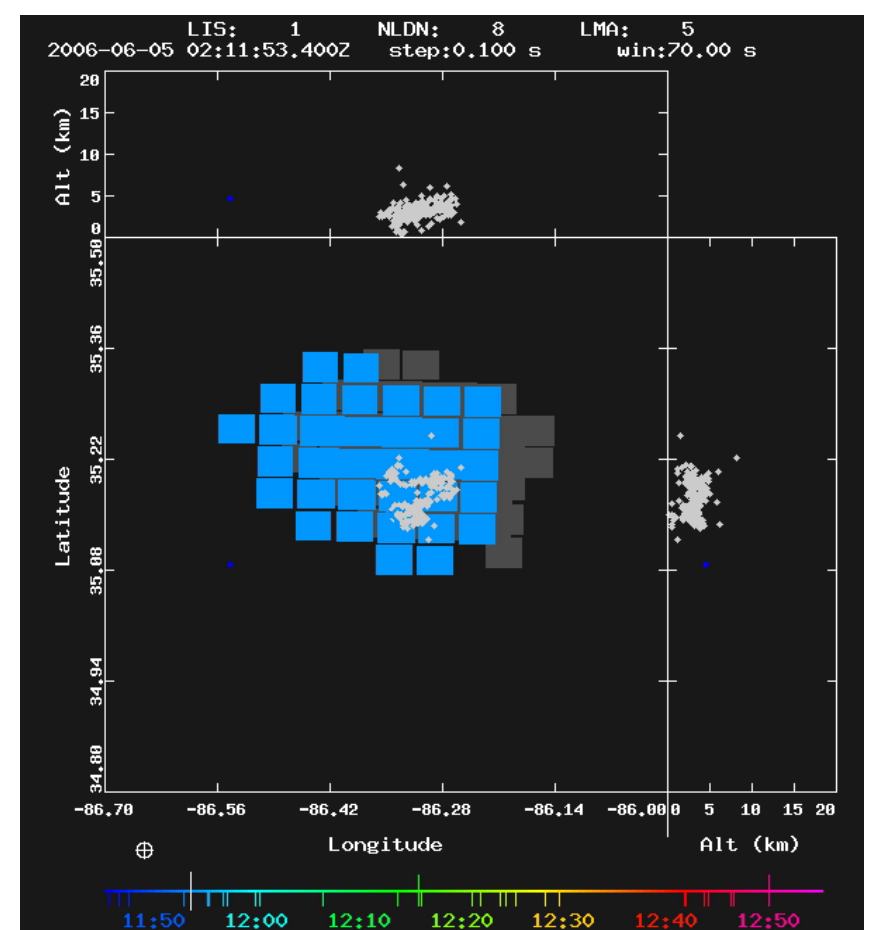

Figure 3. A comparison of the spatial differences of an example flash between an optical observation from the TRMM-LIS (blue/ gray pixels) and the VHF radiation from the North Alabama LMA (gray source points) on 5 June 2006. Each LIS flash location is determined by the amplitude-weighted centroid of the groups/ events. The LMA flash consists of clustered radiation sources recorded at $80-\mu$ s intervals along the path of the flash.

The VILFRD formula is subjectively determined in order to have a trackable product that relies more on radar-based information when flash rates are low, and then transitions to more weight applied towards lightning information when flash rates are high. These two components inside the brackets each are limited to a maximum value of one resulting in maximum VILFRD values of 200 . The maximum limits are set to treat anything larger than moderate VIL values $(\sim 45$ $\mathrm{kg} \mathrm{m} \mathrm{m}^{-2}$ ) the same because this indicates a strong thunderstorm. In addition, flash rates $\geq 45 \mathrm{~min}^{-1}$ also are indicative of a strong thunderstorm. Even though an in-depth comparison between the two tracking methods (i.e., radar only versus radar and lightning combined) has not been completed with this dataset, initial observations place added value to the addition of lightning information compared to radar tracking alone as it increased the consistency of tracking a storm's core and updraft region. This agrees with results from Meyer et al. (2013) who used radar and lightning data to track storms. Lightning and lightning jumps are physically related to the storm's updraft (e.g., Schultz et al. 2015), and thus the combination of radar and lightning information provides the tracking system a product that is weighted towards the most intense part of the storm cluster.

\section{b. Thunderstorm tracking}

To compute lightning time histories for jump identification, it is necessary to utilize an automated, objective tracking scheme to assign lightning flashes to individual storms. VILFRD is tracked using $\mathrm{k}$ means clustering in w2segmotionll in WDSS-II (Lakshmanan et al. 2009). WDSS-II w2segmotionll is used to track features where VILFRD values are $\geq 20$, at increments of 20. Any pixel with a value $>100$ is assigned 100. Clusters are built outward from a local maximum until a minimum size or spatial scale threshold is met (Table 2), with a maximum overlap approach (combining cells within $5 \mathrm{~km}$ of the cell boundary) for associating cells from one time step to the next. Cells are not included that are not tracked at each time step. The WDSS-II tracking included 8 scales (scales 0-7). However, only scales 1-6 are included as scale 0 and scale 7 are unusable because the extremely small and large area parameters, respectively, failed to produce output for the vast majority of cases. The scales are tracked at 40, 80, $120,160,200$, and 300 pixels. The exact area scale thresholds in Table 2 account for the fact that a pixel is $<1 \mathrm{~km}^{2}$. Figure 4 depicts two example clusters used to help describe this tracking method. VILFRD values are denoted by different colors. If VILFRD values $\geq 100$ (red in Fig. 4) meet the required minimum area of a spatial scale threshold, a cluster is identified and the algorithm moves on to other clusters during that time step. If not, the algorithm reduces the VILFRD threshold to the value of 80 and searches for clusters that meet the minimum area of the spatial scale threshold. The VILFRD threshold continues to reduce in increments of 20 until it reaches a floor VILFRD value of 20. If the VILFRD feature footprint at the level of 20 does not reach the minimum area of a spatial scale threshold, no cluster is identified at that time and location. For example, a feature at scale 5minimum required area is $162 \mathrm{~km}^{2}$ (Table 2)-would be represented as the area included in D (VILFRD $\geq 40$ ) in Cluster 1 and as area included in B (VILFRD $\geq 40$ ) for Cluster 2 .

The result of this iterative identification technique is that tracked clusters will differ in area and lifetime at each spatial scale. Each individual cluster is given a unique cluster identification number during its 
Table 2. Spatial scale levels with minimum area required to track storm clusters using WDSS-II, and average storm track duration, length, and cluster size.

\begin{tabular}{|c|c|c|c|c|}
\hline Spatial Scale & $\sim$ Area $\left(\mathbf{k m}^{\mathbf{2}}\right)$ & Track Duration $(\mathbf{h})$ & Track Length $(\mathbf{k m})$ & Cluster Size $\left(\mathbf{k m}^{2}\right)$ \\
\hline 1 & 32 & 1.003 & 42.57 & 122.77 \\
\hline 2 & 65 & 1.032 & 44.80 & 175.57 \\
\hline 3 & 97 & 1.028 & 44.89 & 224.91 \\
\hline 4 & 130 & 1.046 & 46.55 & 270.32 \\
\hline 5 & 162 & 1.039 & 47.15 & 318.23 \\
\hline 6 & 243 & 1.042 & 48.55 & 443.37 \\
\hline
\end{tabular}

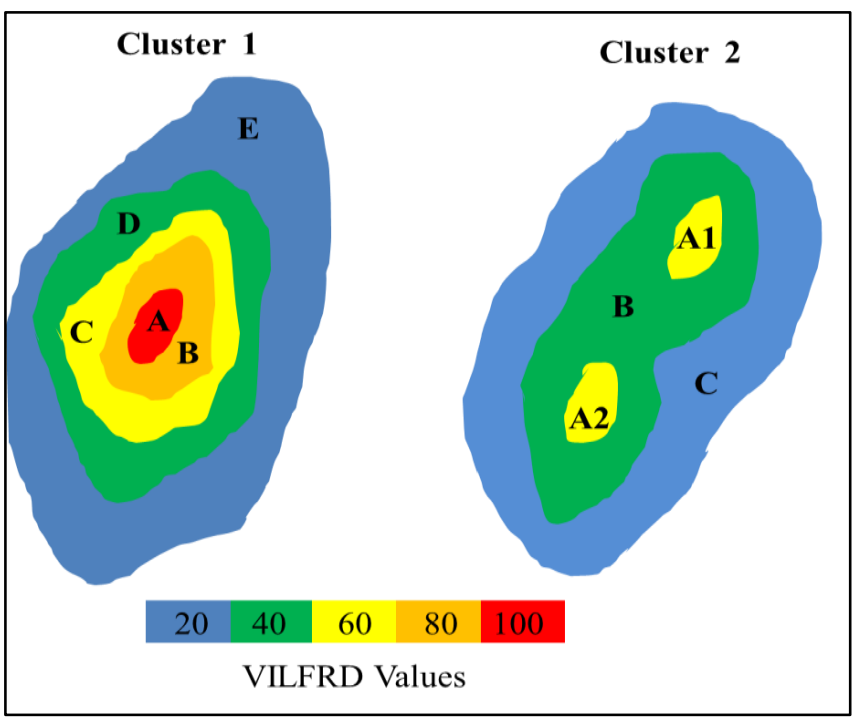

Figure 4. Schematic of two example storm clusters used to describe the VILFRD cluster identification and tracking process at multiple scales. Scale 1: left - cluster A $\left(40 \mathrm{~km}^{2}\right)$, right - cluster A1 $\left(35 \mathrm{~km}^{2}\right)$ and cluster A2 $\left(38 \mathrm{~km}^{2}\right)$. Scale 3: left - cluster B (100 $\left.\mathrm{km}^{2}\right)$. Scale 4: left - cluster C $\left(150 \mathrm{~km}^{2}\right)$. Scale 5: left - cluster D $\left(200 \mathrm{~km}^{2}\right)$, right - cluster B $\left(200 \mathrm{~km}^{2}\right)$. Scale 6: left - cluster E $\left(300 \mathrm{~km}^{2}\right)$, right - cluster C $\left(300 \mathrm{~km}^{2}\right)$.

lifetime. Individual clusters at a select time are shown as an example in Fig. 2d. Outside of WDSS-II, "broken tracks" are objectively merged if a WDSS-II cell begins at $t+1$ within $15 \mathrm{~km}$ of where a previous track ended at time $t$. Time histories are tied together for merged cells.

\section{c. Lightning jump algorithm}

The LJA as defined by S09 laid the foundation for this study. In their studies, S09 and S11 objectively identified lightning jumps using the $2 \sigma$ algorithm. Figure 5 illustrates the flow chart for the following five steps describing the LJA process for the $2 \sigma$ threshold.

1) The total lightning flash rate (as calculated from the 1-min GLM proxy FRD) from the time period, $t$, is binned into 2-min time periods and averaged.

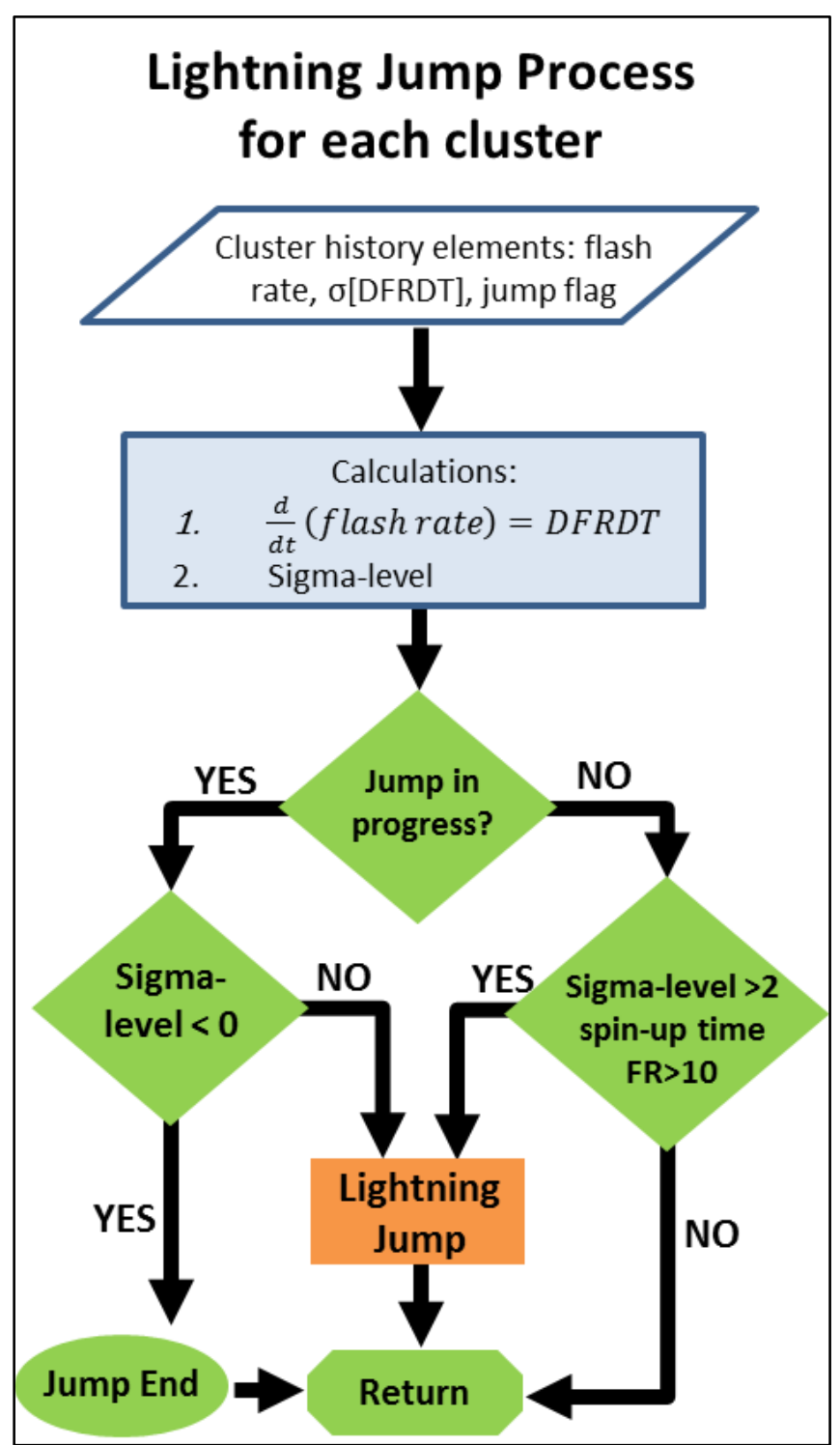

Figure 5. Flowchart for the lightning jump classification process using the $2 \sigma$ algorithm from S09.

2) The time rate of change of the total flash rate (DFRDT) is calculated by subtracting consecutive bins from each other (i.e., $\operatorname{bin}_{2}-\operatorname{bin}_{1}, \operatorname{bin}_{3}-$ bin $_{2}, \ldots$, bin $_{\mathrm{t}}-$ bin $\left._{\mathrm{t}-1}\right)$. This results in DFRDT values with the units of flashes $\min ^{-2}$. 
3) The standard deviation of the five previous DFRDT values is calculated. Twice this standard deviation determines the level for the current DFRDT to exceed to be classified a jump in the $2 \sigma$ algorithm.

4) Taking the ratio of the current DFRDT value to the standard deviation of the previous five time periods (step 3) is further referred to as the sigma-level. Thus, a previously defined $2 \sigma$ jump would have a sigma-level of 2 . This presentation allows the end user to have the ability to understand how a current increase in the total flash rate compares to other recent increases in the storm's total flash rate. For instance, a sigma-level of 8 would indicate a more rapid increase in the flash rate than a sigma-level increase of 2. This extra information directly corresponds to the kinematic and microphysical growth of the storm leading up to the time of the lightning jump and can aid in the forecaster's warning decision making process (Schultz et al. 2015).

5) In addition to reaching the required sigma-level to determine a jump, the following also must be met for the original approach to the algorithm: the minimum spin-up time of $14 \mathrm{~min}$ is reached (six time periods to achieve five DFRDT values plus the current time period), the current flash rate exceeds the flash rate threshold of 10 flashes $\mathrm{min}^{-1}$, and the classification of an individual jump ends once the sigma-level drops below zero.

6) This process is repeated every 2 min as new total lightning flash rates are collected (until the storm dissipates). If a jump is currently in progress, the jump is continued until the sigma-level drops below zero. In the event multiple jumps occur within 6 min of each other, only the first jump remains for verification to follow the original S09 verification method (Table 3).

Table 3. A comparison of verification methods between the method used in S09/S11 and a method aligning with the NWS.

\begin{tabular}{|c|c|c|}
\hline $\begin{array}{c}\text { Verification } \\
\text { Methods }\end{array}$ & $\begin{array}{c}\text { Verification } \\
\text { (S09/S11) }\end{array}$ & $\begin{array}{c}\text { Verification } \\
\text { (NWS) }\end{array}$ \\
\hline $\begin{array}{c}\text { Storm report } \\
\text { grouping }\end{array}$ & Yes (6 min) & No \\
\hline $\begin{array}{c}\text { One storm report } \\
\text { verifies two } \\
\text { overlapping forecasts }\end{array}$ & $\begin{array}{c}\text { No (only first forecast, 1 } \\
\text { hit) }\end{array}$ & Yes (1 hit) \\
\hline Jump grouping & Yes (6 min) & Yes (6 min) \\
\hline False alarm & $\begin{array}{c}\text { No report during forecast } \\
\text { OR for overlapping } \\
\text { forecasts; no report in time } \\
\text { period following first } \\
\text { forecast expiration }\end{array}$ & $\begin{array}{c}\text { No report during } \\
\text { forecast }\end{array}$ \\
\hline
\end{tabular}

\section{d. Parameter sensitivity testing}

Seven parameters (Table 1) within the lightning jump system have been identified as having potential impact on the performance of the LJA. A range of values for sigma-level threshold, flash rate threshold, spin-up time, severe storm report distance, verification window, domain range, and spatial scale is used to determine for which parameters the algorithm is the most sensitive to, and what those values are. With the initial development of the LJA, S09 tested a $2 \sigma$ and $3 \sigma$ configuration of the LJA and determined that the $2 \sigma$ version produced more optimal skill scores when the 10 flashes $\min ^{-1}$ threshold is implemented. Based on the S09 findings, the $2 \sigma$ configuration was tested further in S11. This study expands upon the LJA configuration results from S09 and S11-and further exploration by Chronis et al. (2015) - through additional sensitivity testing of the sigma-level threshold by varying the sigma-level from 0.75 to 2.5 in 0.25 increments (Table 1). Furthermore, a range of flash rate thresholds $(1,5,10,15$, and 20$)$ is tested in order to determine the algorithm sensitivity (Table 1). The minimum time required for the spin-up of the algorithm is $14 \mathrm{~min}$ (12 min to calculate the sigma-level, 2 additional minutes to determine if a lightning jump has occurred; section 2c).

Tunable parameters that are investigated within the verification framework are severe storm report distance and verification window. Severe storm reports were obtained from the National Centers for Environmental Information's (NCEI, formerly the National Climatic Data Center) Storm Data and used as ground truth for validation. Storm Data has known temporal and spatial errors in reporting of events and known underreporting in data-sparse regions (e.g., Witt et al. 1998; Williams et al. 1999; Trapp et al. 2006; Chronis et al. 2015), so effort is taken to mitigate small timing and spatial errors that may exist in the database. This mitigation includes an additional buffer space around the footprint of a tracked storm cluster at each time step to assign reports to specific clusters. Storm report distance is defined as the maximum distance from the storm cluster's footprint edge that a storm report can be associated with that storm. This distance is set to 5 $\mathrm{km}$ (Table 1). The verification window starts at the occurrence of a jump and lasts for $45 \mathrm{~min}$ (Table 1). Reports that occur within this verification window are used to verify the jump. For the results shown within, these parameters remained constant as initial sensi- 
tivity testing showed less impact to the overall system performance than for the other parameters.

Finally, two parameters are used to ensure quality and define the database. The domain range is limited to the areal coverage of the LMA network (Fig. 1). The closer the lightning activity is to the network, the higher the detection efficiency (Koshak et al. 2004). Therefore, extending the domain can decrease the detectable flashes and flash rates that can have an effect on the classification of jumps. A default distance is chosen as $125 \mathrm{~km}$ to remain proximate to the LMA network, which is used to statistically generate the GLM proxy data. Only portions of the storm life cycle (inclusion of entire storm's footprint determined by the storm's centroid location) occurring for $\geq 30 \mathrm{~min}$ within $125 \mathrm{~km}$ of the center of the LMA network are included in this study. The variance in spatial scale introduced in this study is a result of the options available in w2segmotionll in WDSS-II to track features at different areal extents. Six different spatial scales (Table 2) are chosen ranging in sizes from that of small thunderstorms (scale 1 at $32 \mathrm{~km}^{2}$ ) to that of larger storm clusters (scale 6 at $243 \mathrm{~km}^{2}$ ). These values serve as the benchmark storm size for the sensitivity testing of the LJA.

\section{e. Verification}

The verification method initially applied in this study closely reflects the method outlined in S09. In order to evaluate the lightning jump system, severe storm reports are used as ground truth validation. As mentioned in section $2 \mathrm{~d}$, there are caveats with using NCEI Storm Data. In an attempt to mitigate these effects, a temporal clustering of reports (same type) in 6-min bins is implemented. This binning begins at the time of the first report. Any report grouped into this bin counts as a single event and the time of the first report within the group is used for any calculations.

The window for jump verification is the time window (default length of $45 \mathrm{~min}$; Table 1) starting at the time of the jump. However, in the method outlined by S09, only one jump can be evaluated at a given time. As mentioned in section $2 \mathrm{~d}$, jumps are grouped together if they occur within 6 min of each other (three consecutive time periods). This leaves open the potential for additional jumps to occur within the verification window (after the 6-min grouping) of a previous jump. In these cases, initial or "first" jumps and subsequent or "second" jumps are denoted as shown in Fig. 6. Each jump has a verification window

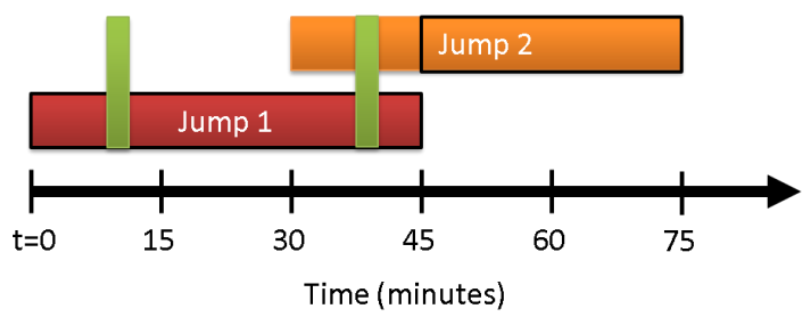

Figure 6. A schematic of respective verification windows for two lightning jumps (red and orange boxes). Following the verification method found in S09, only one jump can be verified at a given time with the given example storm reports (vertical green rectangles). Therefore, jump 2 is not able to validate until after jump 1's verification period has ended. The black rectangles indicate the valid time period for each jump.

equal to that of the verification window parameter, which is $45 \mathrm{~min}$ for this study. The first jump is verified and a "hit" (defined as the number of storm report groups within the verification window) if a storm report occurs during the verification window as denoted by the green vertical bar at approximately 10 min in Fig. 6. A second jump's verification window, however, is limited to the time period remaining following the expiration of the first jump's verification window. For example, if the second jump started 30 min after the first, its verification window would begin 15 min later (considering a 45-min verification window) leaving a 30-min verification window for the second jump. This can be visualized in Fig. 6. Despite what reports exist within the 15-min overlap of the two jumps (between 30 and $45 \mathrm{~min}$, or for example, a report at approximately $40 \mathrm{~min}$ ), the second jump is classified as a false alarm if no reports are present for the remaining $30 \mathrm{~min}$ (between 45 and $75 \mathrm{~min}$ ). This method is applied for any additional jumps.

In order to evaluate the algorithm, the skill scores of POD and FAR (Wilks 2011, pp. 310-311) are calculated. In this process, a hit is defined as the grouped severe storm reports that occur during a verification window of a jump within the set bounds around a storm cluster (based on the radius from the edge of the cluster's footprint). A miss is defined as a severe storm report group that occurs outside of a verification window. A false alarm is defined as a jump that is not followed by any severe storm reports within the associated verification window as well as the qualification involving subsequent jumps as described in the previous paragraph.

The verification method from S09/S11 is not equivalent to that of the method employed by the NWS storm warning verification (NWS 2011). The main difference that exists between these two is the 
grouping of severe storm reports and the false alarm classification for subsequent jumps. A side by side comparison of these two methods can be seen in Table 3. Unlike S09, the NWS validates each warning separately even if they overlap. However, reports in the overlapping region only count as a single hit and not a hit for each warning. In an effort to more closely compare our results to the techniques used by the NWS, we included what we will call an alternative (in reference to the S09 verification method). The discussion of our results will use both of these verification methods to evaluate the LJA algorithm and analyze sensitivity within the tunable parameters listed in Table 1.

\section{Results}

Numerous iterations of tunable parameter combinations (Table 1) were (i) processed through the lightning jump system, (ii) analyzed, and (iii) evaluated using the skill score metrics of POD and FAR. The sensitivity analysis revealed the level of influence that individual parameters and parameter combinations have on the system performance. In addition, the verification methods notably affected the evaluation of the lightning jump system. The key results shown are the influence of spatial scale used in storm cluster tracking, the effect of sigma-level and the flash rate threshold on the LJA, and the impact the verification method has on these results.

\section{a. Spatial scale}

One component of the tracking method is choosing a representative storm scale size. However, storm size and appropriate scale size can vary greatly depending on storm mode. Scales ranging in areal size from scale 1 at $32 \mathrm{~km}^{2}$ to scale 6 at $243 \mathrm{~km}^{2}$ (Table 2) were tested. Figure 7 shows cluster footprints for all six scales discussed in this study at a given time (same date/time as Fig. 2). This figure depicts the similarities and differences inherent to the different tracking scales. Most notably different is cluster A on the lefthand side of the figures, which varies drastically in size from scale 1 to scale 6 . Cluster B remains the same size throughout the different scales. This consistent size is most likely due to a strong, active lightning core within this thunderstorm as can be noted by the influence of the lightning contribution to VILFRD as seen in Figs. 2a, b, and c.

Figure 8 shows a color-coded comparison between the six different spatial scales that are used by WDSSII to track storm clusters. Each symbol represents one iteration of the algorithm for all event days for a given set of parameters. Larger spatial scales show increased POD values due mainly to the large areal extent of the storm clusters' footprints. Quantitative evidence of this is shown in Tables 4 and 5. These larger areal extents allow for the inclusion of more lightning flashes and, thus, higher flash rates. More than $37 \%$ of time steps in the scale 6 database have flash rates $>20 \mathrm{~min}^{-1}$. At the lower spatial scales the flash rates often do not reach the minimum flash rate threshold (default of 10 flashes $\mathrm{min}^{-1}$ ). This is true for $87 \%$ of time steps for the entire scale 1 database. In contrast, only $22 \%$ of time steps at scale 6 have total flash rates below 10 flashes $\mathrm{min}^{-1}$. In scale $1,4.5 \%$ of the database reaches a sigma-level of 2 but are not calculated as jumps because the flash rate is $<10$ flashes $\mathrm{min}^{-1}$. Not meeting the minimum flash rate threshold prevents the LJA from activating and leads to any event occurring within the areal bounds set for that storm to be considered a miss. This causes both an increase in the number of misses and a decrease in the relative amount of hits as compared to larger scales and, thus, leads to lower POD values in the smaller scales. POD values increase from a range of 0.19 to 0.88 at scale 1 to 0.44 to 0.97 at scale 6 (due to a variance of other parameters). The range of FAR values between scales shows less spread than for POD. The range of values decreases with increasing spatial scales, from a range of 0.50 to 0.91 at scale 1 to 0.63 to 0.86 at scale 6 .

During early investigation of the interplay between spatial scale and storm tracking, it was found that smaller scales are more ideal for isolated, small-scale thunderstorms as they are easier for the tracking algorithm to separate. Larger scales are more ideal for more complex and larger storms such as supercells. The larger scales are less likely to split apart a cluster that would naturally be considered as one entity, although it may consist of multiple updrafts. In order to evaluate flash rate threshold and sigma-level, an optimal scale needs to be selected. Scale 5 (minimum areal size of $162 \mathrm{~km}^{2}$ ) was selected based on the balance of a high number of verified jumps per cluster $(0.30$, Table 5) with fewer missed events per cluster (0.26, Table 5). Scale 5 also balances the penalty of increasing FAR as it increases less than the POD increases with larger scales. While all scales 1 through 6 are explored in this research, scale 5 is fixed for analysis and comparisons shown herein. 

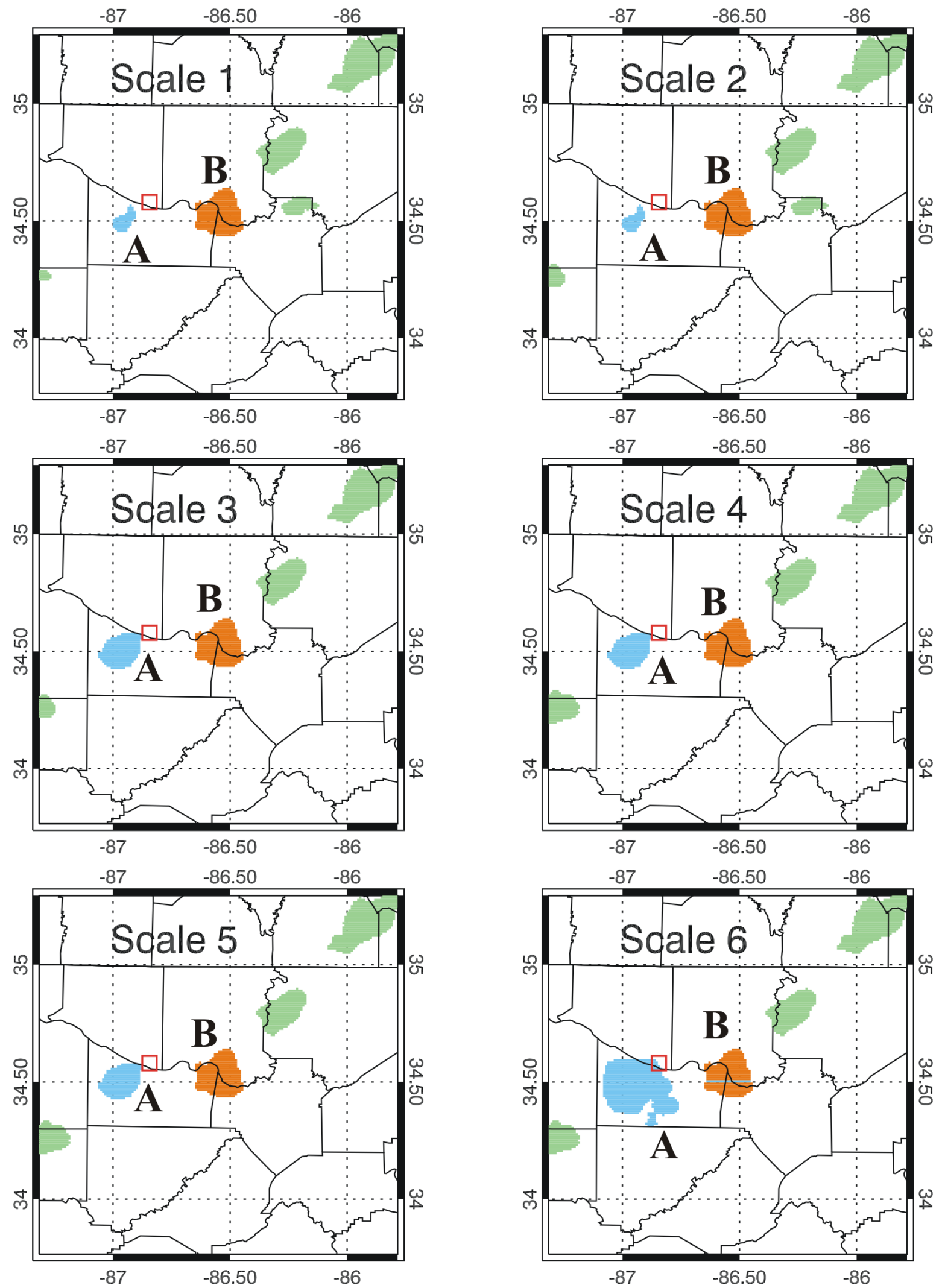

Figure 7. Cluster footprint comparisons for scale 1 (upper left) to scale 6 (lower right) at 1945 UTC 10 April 2009, the same time shown as in Fig. 2. Storm A is blue and the same as cluster 88 in Fig. 2d. Storm B is in orange and the same as cluster 32 in Fig. 2d. The storm report plotted with the red square represents a missed wind report. 


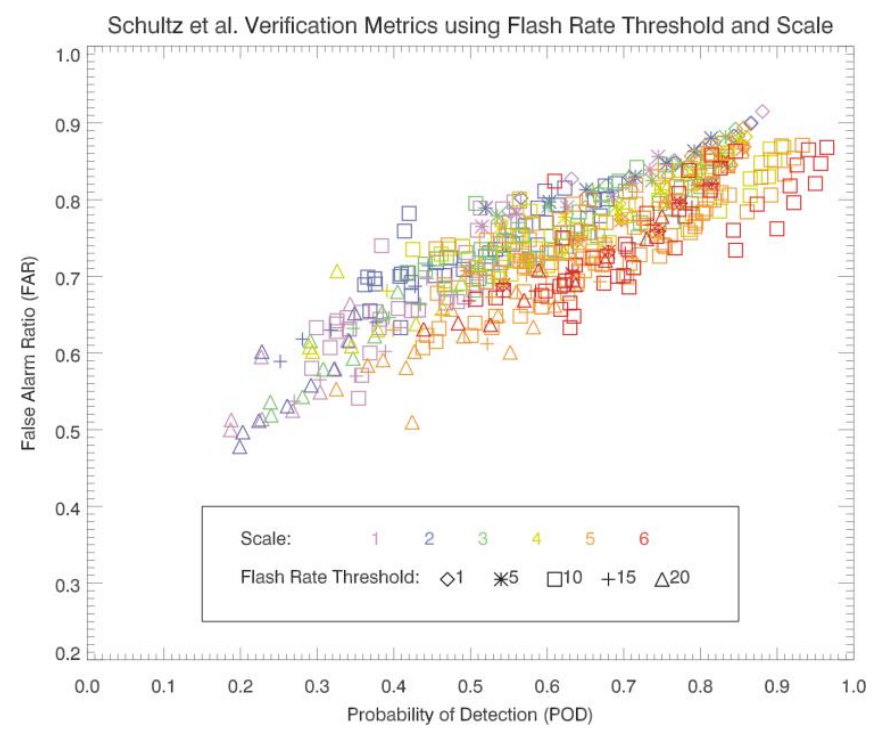

Figure 8. FAR versus POD comparison of the 6 spatial scales (areal extent). Colors represent the spatial scale at which storms are tracked and symbols represent flash rate thresholds for the S09 verification method. Each symbol represents one iteration of the algorithm for all event days for a set of given parameters.

\section{b. Algorithm parameters: Flash rate threshold and sigma-level}

Compared to all the tunable parameters listed in Table 1, the combined effects of the flash rate threshold and sigma-level show the most promise in improving the LJA performance as evaluated by POD and FAR. The POD and FAR values for the sigmalevel and flash rate thresholds for the S09 and alternative verification methods are shown in Figs. 9 and 10, respectively. The S09 verification method (Fig. 9) shows that decreasing the sigma-level values (cooler colors) and lowering the flash rate threshold (symbols) results in the POD increasing slightly more than the increasing FAR. The POD and FAR are strongly coupled with a coefficient of determination of 0.95. In order to help break down the individual effects of sigma-level and flash rate towards POD and FAR, a linear regression model is applied at each constant sigma-level or flash rate. The trends of the slope of the linear regression models show that as the sigma-level decreases, the effect of flash rate become more pronounced (slope or rate of change of 0.88 at 2.5 sigma-level and 0.57 at 0.75 sigma-level). These slopes help reveal a smaller increase in FAR values with increasing POD values.

The overall effect of sigma-level and flash rate threshold on the algorithm with the alternative verification (Fig. 10) shows a decoupled POD-FAR relationship $\left(R^{2}=0.20\right)$. This is noted by little change

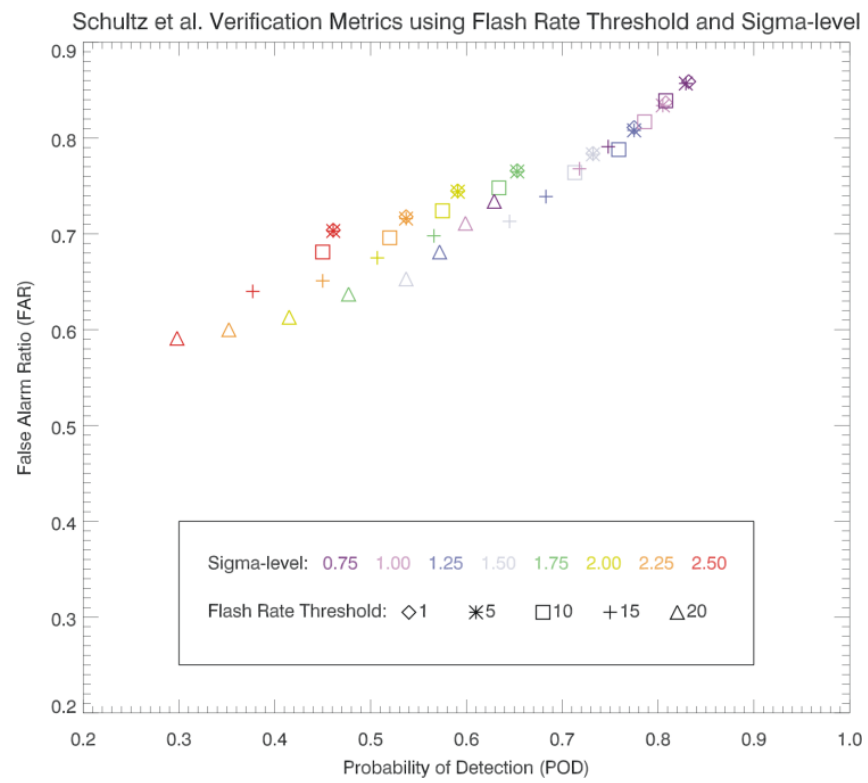

Figure 9. FAR versus POD comparisons using the S09 verification method showing the relationship of sigma-level (color) and flash rate threshold (symbols) on the algorithm's performance at spatial scale 5. Flash rate thresholds of 1 (diamond) and 5 (asterisk) flashes min $^{-1}$ are very similar at each sigma-level and may be difficult to discern. A linear regression analysis $(y=0.52 x+0.40)$ for these data resulted in a strong correlation between POD and FAR $\left(\mathrm{R}^{2}=\right.$ 0.95). A linear regression analysis while holding each sigma-level constant resulted in $\mathrm{R}^{2}=0.99$ with slopes ranging from 0.57 (at the 0.75 sigma-level) to 0.88 (at the 2.5 sigma-level).

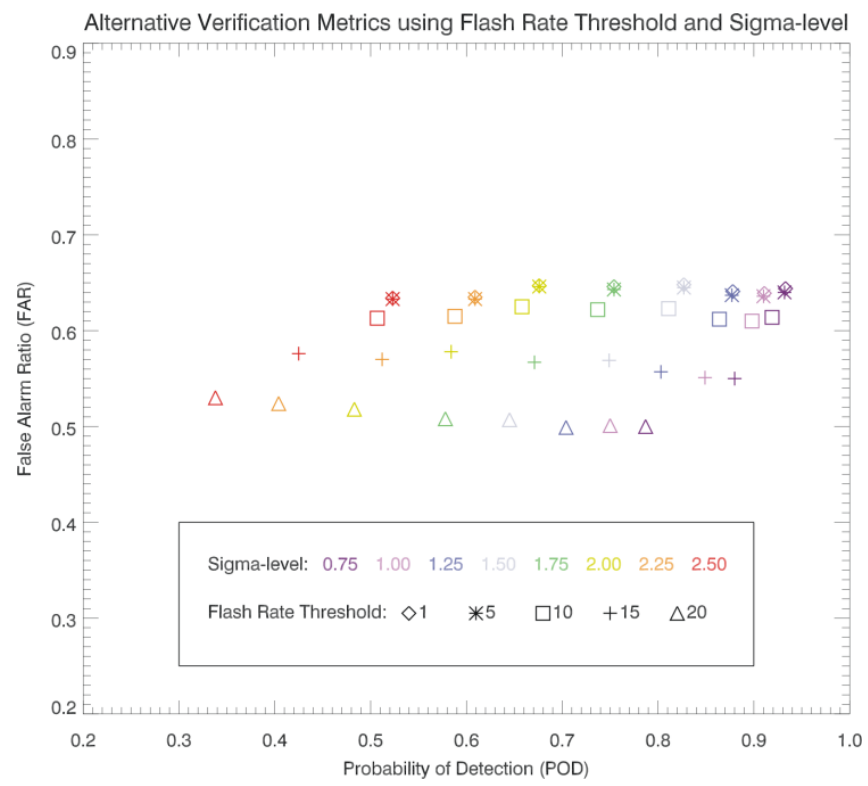

Figure 10. Same as Fig. 9 except for the alternative verification method. A linear regression analysis $(y=0.16 x+0.48)$ for these data resulted in almost no correlation between POD and FAR $\left(\mathrm{R}^{2}=\right.$ 0.20). A linear regression analysis while holding each sigma-level constant resulted in $\mathrm{R}^{2}$ values $>0.9\left(\mathrm{R}^{2}=0.93\right.$ to 0.99$)$ and slopes ranging from 0.99 (at the 0.75 sigma-level) to 0.59 (at the 2.5 sigma-level). 
Table 4. Total scale attributes using the S09/S11 and alternative verification methods.

\begin{tabular}{|c|c|c|c|c|c|c|c|}
\hline Scale & Clusters & Jumps & False Alarms & Hits & Misses & $\begin{array}{c}\text { Alt. False } \\
\text { Alarm }\end{array}$ & \begin{tabular}{c} 
Alt. Hits \\
\hline $\mathbf{1}$
\end{tabular} \\
\hline $\mathbf{2}$ & 1121 & 505 & 378 & 200 & 330 & 344 & 276 \\
\hline $\mathbf{3}$ & 978 & 724 & 567 & 233 & 311 & 519 & 323 \\
\hline $\mathbf{4}$ & 842 & 1044 & 760 & 274 & 259 & 705 & 279 \\
\hline $\mathbf{5}$ & 737 & 992 & 858 & 285 & 219 & 801 & 387 \\
\hline $\mathbf{6}$ & 583 & 851 & 769 & 295 & 194 & 725 & 430 \\
\hline
\end{tabular}

Table 5. Normalized scale attributes by number of clusters using the S09/S11 and alternative verification methods.

\begin{tabular}{|c|c|c|c|c|c|c|c|}
\hline Scale & Jumps & Hits & False Alarms & Misses & Verified Jumps & $\begin{array}{c}\text { Alt. False } \\
\text { Alarms }\end{array}$ & Alt. Hits \\
\hline $\mathbf{1}$ & 0.37 & 0.15 & 0.27 & 0.24 & 0.09 & 0.25 & 0.20 \\
\hline $\mathbf{2}$ & 0.65 & 0.21 & 0.51 & 0.28 & 0.14 & 0.46 & 0.29 \\
\hline $\mathbf{3}$ & 0.97 & 0.28 & 0.78 & 0.26 & 0.19 & 0.72 & 0.29 \\
\hline $\mathbf{4}$ & 1.24 & 0.34 & 1.02 & 0.26 & 0.22 & 0.95 & 0.46 \\
\hline $\mathbf{5}$ & 1.35 & 0.40 & 1.04 & 0.26 & 0.30 & 0.98 & 0.58 \\
\hline $\mathbf{6}$ & 1.46 & 0.50 & 1.14 & 0.29 & 0.32 & 1.04 & 0.70 \\
\hline
\end{tabular}

in the FAR and an increase in the POD with decreasing sigma-level values. In addition, decreasing the flash rate threshold leads to an increase in FAR and POD, with FAR increasing at a slightly lower rate of change than the POD. The addition of more storms meeting the low flash rate requirements allows for jumps to be calculated (whereas the algorithm would not be initialized at higher flash rates) and more storm reports to be counted as potential hits. A linear regression analysis, while holding the sigma-level constant, reveals linear regression fits (or slopes) of 0.99 (at 0.75 sigma-level) to 0.59 (at 2.5 sigma-level). This quantifies the coupled effect that flash rate threshold has on the POD-FAR relationship at low sigma-level values and the decoupling of this relationship with increasing values of the sigma-level. Thus, the sigmalevel contributes to the overall decoupled POD-FAR relationship with the alternative verification.

\section{c. Verification methods}

Two similar yet different verification methods are explored for this study. Figure 11 shows the spread of the verification method established in S09 (black) and the alternative verification method (red) for all spatial scales. As mentioned, the S09 verification shows how closely coupled the relationship is between POD and FAR. The alternative method of verification shows improved performance of the LJA system on the order

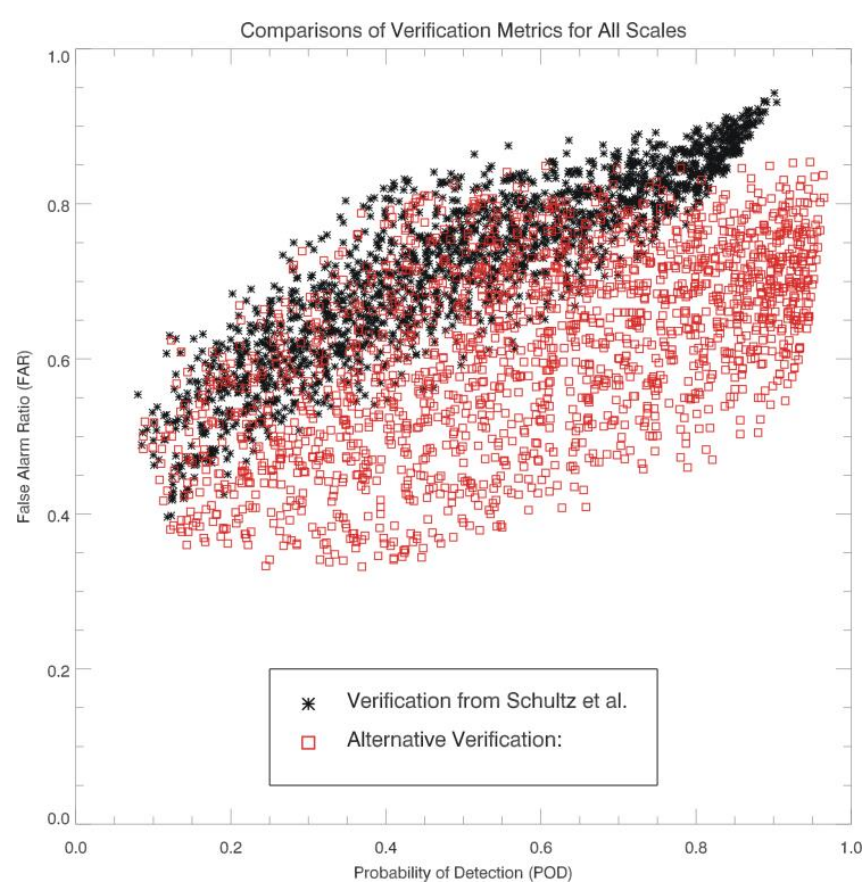

Figure 11. A complete dataset distribution, from all ranges of sensitivity testing, showing FAR versus POD comparisons of the differences between the S09 verification (black) and alternative verification (red) methods.

of reducing the FAR by $20 \%$ while maintaining a high POD. This is most likely due to the reduced amount of subsequent jumps classified as false alarms in S09's method (Table 4). 
Figure 12 shows a comparison of the two methods for an individual cluster track. The difference comes in the classification of a jump that occurs during the verification window of a previous jump. The difference between the two methods is evident in the fourth jump, or jump D. Under the method in S09, jump $\mathrm{D}$ is a false alarm because the severe events that follow jump $\mathrm{D}$ also are in the verification window of jump C. If an event is reported after the verification window of the previous jump, then jump D would be a hit or verified jump in the S09 method. Jump D is a hit, or verified jump, in the alternative verification because that method removes the restriction of only allowing one jump to be verified at a given time. While false alarms and hits will be different between the two methods owing to the reasons discussed above, the number of misses remains constant as no jumps are created or removed that could increase or reduce the number of misses.

\section{Discussion and summary}

Storm tracking is a challenging aspect of research at the storm scale. Previous tracking methods have involved radar reflectivity thresholds, radar reflectivity at specific temperature thresholds, satellite features, etc. This study has taken a new, unique approach and combined VIL and gridded lightning flash rate density to develop a trackable product. This product, VILFRD, helps track the portions of the storm where relevant ice production and lightning activity are occurring in order to focus on the intense portions of the storm. Most importantly, this method of utilizing lightning information - in addition to radar-derived parameters-1 lays groundwork for future methods of tracking storms by lightning in the absence of radar information (e.g., over oceans, in terrain where radars encounter blockage). This type of tracking is potentially game changing from the perspective of GOES-R. With $G O E S-R$, the community will have the ability for hemispheric tracking of storm systems with the added lightning capabilities of the GLM, providing additional information on the intensity of storms not only over land, but also in data-sparse regions.

One of the key points of this study is the testing of various spatial scales in storm tracking. Table 2 documents these various scales. As is noted, results differed based on spatial scale. A large part of this result is the inability for the lightning flash count within the smaller spatial scales to reach a minimum threshold. For some of the clusters in the smaller scales, the tracked feature is a more intense core within what is tracked as a larger multicell cluster at larger spatial scales. This is an advantage when trying to separate features to trackable sizes, but a disadvantage when verification techniques are applied and smaller clusters perform poorly because of only covering a limited spatial area. There has been initial research and testing into combining different scales (Herzog et al. 2014).

Both sigma-level and flash rate play an important role in the lightning jump system's ability to predict severe storms, especially based on the results shown for the S09/S11 method. Recent work by Chronis et al. (2015) and Schultz et al. (2015) demonstrate both empirically and physically how these two parameters work in concert with each other and provide valuable information into the intensification of storms. The lightning jump provides lead time on the higher flash rates that are to come, and higher flash rates are physically and dynamically tied to the development and manifestation of severe weather at the surface. There are notable differences in skill scores between this study ( 60\% POD and 73\% FAR) and S11 (79\% POD and $35 \%$ FAR), despite using the same event days from the Tennessee Valley. The most obvious difference between the two studies is in the number of clusters/storms. The automated tracking employed in this study identified more storm clusters in the same event database at each spatial scale (Table 1) than the 555 storms identified in S11. Another key difference is the lightning data input. In general, the GLM proxy data have fewer flashes identified than the full LMA dataset used in S11. When the alternative method is applied, the sigma-level influences the performance of the algorithm to a larger extent than the flash rate threshold. Decreasing the sigma-level will increase the number of jumps and will increase the likelihood of event detection (increase in POD). In the alternative method, the algorithm is not penalized the same as the S11 method for repetitive or subsequent jumps that overlap with previous jump forecasts. Therefore, this increase in jumps does not increase FAR. In actuality, the FAR decreases with decreasing sigma-level because the added number of jumps associated with a lower sigma-level threshold are not penalized for overlapping.

For both verification methods, the increase of the flash rate threshold reduces the number of jumps. In turn, this decreases the FAR (jumps are not identified until they reach a higher flash rate) and POD because many severe events are counted as missed events 

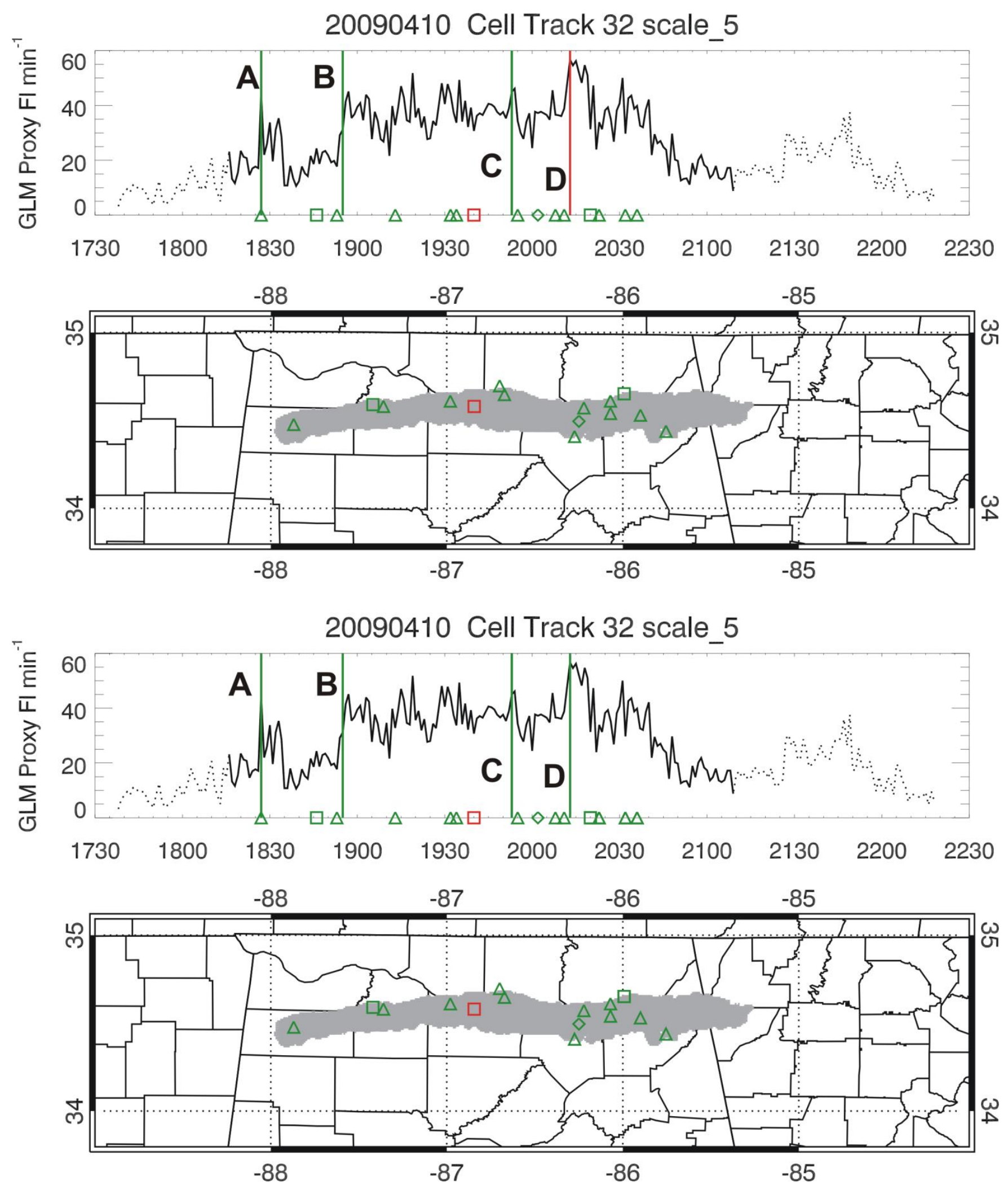

Figure 12. Similar to Fig. 2e except for a comparison of verification methods for a single example case. The top half of the figure shows the S09 verification method and the bottom half shows the alternative verification method applied. The key difference is the classification of the fourth jump (jump D) as a false alarm in the top image and a hit in the bottom image. 
owing to no jump or forecast being issued. The change in FAR and POD is most notable at smaller spatial scales. Flash rate threshold changes, independent of sigma-level, weakly influence the skill score metrics more using the $\mathrm{S} 11$ verification method.

Finally, it is important to determine how this LJA system can be applied to real-time operations utilizing hemispheric lightning coverage with GOES-R GLM as the launch of GOES-R approaches. The LJA is shown to add value in the operational forecasting paradigm from a satellite, hemispheric perspective (e.g., Darden et al. 2010). Allowing forecasters the ability to evaluate the LJA through tracked clusters, color-coded by sigma-level, as seen in the Hazardous Weather Testbed (HWT; Calhoun et al. 2014), also allows for individual assessment of the variations of sigma-level presented in this and other studies. Tracking methods also greatly can impact the usability of any algorithm (including the LJA), as is shown by this study. The best results are achieved when there is a balance between small and large feature tracking methods. Scale $5\left(162 \mathrm{~km}^{2}\right.$ or about $13 \mathrm{~km} \times 13 \mathrm{~km}$ cluster size $)$ exhibited this balance and is just smaller than that used by the HWT tracking used for real-time lightning jump evaluation.

This work summarizes a technique that combines radar and lightning information to track thunderstorms to assess storm intensity for operational weather applications. Validation using Storm Data shows that key components of the algorithm (flash rate and sigma-level thresholds) have the greatest influence on the performance of the algorithm. The analysis of the lightning jump system using GLM proxy data has shown POD values around 60\% with FAR around $73 \%$ using a similar method to S11 that had a POD of $79 \%$ and a FAR of 36\%. However, when applying verification methods similar to those employed by the NWS, POD values increase slightly $(69 \%$, range of $35-95 \%)$ and FAR values decrease (63\%, range of 48$66 \%)$. These results show that the POD and FAR are highly correlated $\left(R^{2}=0.95\right)$ in the $S 11$ verification but not in the alternative verification $\left(R^{2}=0.20\right)$. This evaluation also highlights the sensitivity of the algorithm's evaluation based on verification methods involving storm reports.

Acknowledgments. This research has been supported by the GOES-R Risk Reduction Research (R3) program. In particular, the authors thank Dr. Steven Goodman, Senior (Chief) Scientist, GOES-R System Program, for his guidance and support throughout this effort. Finally, we thank the two anonymous reviewers for thorough and constructive reviews that improved the content and structure of this article.

\section{REFERENCES}

Bateman, M., 2013: A high-fidelity proxy dataset for the Geostationary Lightning Mapper (GLM). Preprints, Sixth Conf. on the Meteorological Applications of Lightning Data. Austin, TX, Amer. Meteor. Soc., 725. [Available online at ams.confex.com/ams/93Annual/ webprogram/Paper223473.html.]

, D. Mach, E. W. McCaul, J. Bailey, and H. J. Christian, 2008: A comparison of lightning flashes as observed by the lightning imaging sensor and the North Alabama lightning mapping array. Preprints, Third Conf. on Meteorological Applications of Lightning Data. New Orleans, LA, Amer. Meteor. Soc., 8.6. [Available online at ams.confex.com/ams/88Annual/ techprogram/paper_133906.htm.]

Calhoun, K. M., T. M. Smith, D. M. Kingfield, J. Gao, and D. J. Strensrud, 2014: Forecaster use and evaluation of real-time 3DVAR analyses during severe thunderstorm and tornado warning operations in the Hazardous Weather Testbed. Wea. Forecasting, 29, 601-613, Crossref.

Chronis, T., L. D. Carey, C. J. Schultz, E. V. Schultz, K. M. Calhoun, and S. J. Goodman, 2015: Exploring lightning jump characteristics. Wea. Forecasting, 30, 23-37, Crossref.

Darden, C. B., D. J. Nadler, B. C. Carcione, R. J. Blakeslee, G. T. Stano, and D. E. Buechler, 2010: Utilizing total lightning information to diagnose convective trends. Bull. Amer. Meteor. Soc., 91, 167-175, Crossref.

Gatlin, P. N., and S. J. Goodman, 2010: A total lightning trending algorithm to identify severe thunderstorms. $J$. Atmos. Oceanic Technol., 27, 3-22, Crossref.

Goodman, S. J., and Coauthors, 2013: The GOES-R Geostationary Lightning Mapper (GLM). Atmos. Res., 125-126, 34-49, Crossref.

Herzog, B. S., K. M. Calhoun, and D. R. MacGorman, 2014: Total lightning information in a 5-year thunderstorm climatology. Preprints, Int. Conf. on Atmospheric Electricity, Norman, OK, National Severe Storms Laboratory, P-11-16. [Available online at www.nssl.noaa.gov/users/mansell/icae2014/preprints/H erzog 325.pdf.]

Koshak, W. J., and Coauthors, 2004: North Alabama Lightning Mapping Array (LMA): VHF source retrieval algorithm and error analyses. J. Atmos. Oceanic Technol., 21, 543-558, Crossref.

Kummerow, C., W. Barnes, T. Kozu, J. Shiue, and J. Simpson, 1998: The Tropical Rainfall Measuring 
Mission (TRMM) sensor package. J. Atmos. Oceanic Technol., 15, 809-817, Crossref.

Lakshmanan, V., T. Smith, K. Hondl, G. J. Stumpf, and A. Witt, 2006: A real-time, three-dimensional, rapidly updating, heterogeneous radar merger technique for reflectivity, velocity, and derived products. Wea. Forecasting, 21, 802-823, Crossref.

, G. Stumpf, and K. Hondl, 2007: The Warning Decision Support System-Integrated Information. Wea. Forecasting, 22, 596-612, Crossref.

, K. Hondl, and R. Rabin, 2009: An efficient, generalpurpose technique for identifying storm cells in geospatial images. J. Atmos. Oceanic Technol., 26, 523-537, Crossref.

Mach, D. M., H. J. Christian, R. J. Blakeslee, D. J. Boccippio, S. J. Goodman, and W. L. Boeck, 2007: Performance assessment of the Optical Transient Detector and Lightning Imaging Sensor. J. Geophys. Res., 112, D09210, Crossref.

McCaul, E. W., Jr., S. J. Goodman, K. M. LaCasse, and D. J. Cecil, 2009: Forecasting lightning threat using cloudresolving model simulations. Wea. Forecasting, 24, 709-729, Crossref.

Meyer, V. K., H. Höller, and H. D. Betz, 2013: Automated thunderstorm tracking: Utilization of three-dimensional lightning and radar data. Atmos. Chem. Phys., 13, 5137-5150, Crossref.

NWS, cited 2016: National Weather Service instruction 101601: Operations and services performance. [Available online at www.nws.noaa.gov/directives/sym/pd010 16001curr.pdf.]

Proch, D. A., 2010: Assessment of lightning jump algorithm using GOES-R GLM proxy data for severe weather detection. M.S. thesis, Dept. of Atmospheric Sciences, University of Alabama in Huntsville, 64 pp.
Rudlosky, S. D., and H. E. Fuelberg, 2013: Documenting storm severity in the mid-Atlantic region using lightning and radar information. Mon. Wea. Rev., 141, 3186-3202, Crossref.

Schultz, C. J., W. A. Petersen, and L. D. Carey, 2009: Preliminary development and evaluation of lightning jump algorithms for the real-time detection of severe weather. J. Appl. Meteor. Climatol., 48, 2543-2563, Crossref. and 2011: Lightning and severe weather: A comparison between total and cloud-to-ground lightning trends. Wea. Forecasting, 26, 744-755, Crossref.

, L. D. Carey, E. V. Schultz, and R. J. Blakeslee, 2015: Insight into the kinematic and microphysical processes that control lightning jumps. Wea. Forecasting, 30, 1591-1621, Crossref.

Smith, T. S., and Coauthors, 2016: Multi-Radar MultiSensor severe weather and aviation products: Initial operating capabilities. Bull. Amer. Meteor. Soc., in press, Crossref.

Trapp, R. J., D. M. Wheatley, N. T. Atkins, R. W. Przybylinski, and R. Wolf, 2006: Buyer beware: Some words of caution on the use of severe wind reports in postevent assessment and research. Wea. Forecasting, 21, 408-415, Crossref.

Wilks, D. S., 2011: Statistical Methods in the Atmospheric Sciences. 3rd ed. Academic Press, 676 pp.

Williams, E. R., and Coauthors, 1999: The behavior of total lightning activity in severe Florida thunderstorms. Atmos. Res., 51, 245-265, Crossref.

Witt, A., M. D. Eilts, G. J. Stumpf, J. T. Johnson, E. D. Mitchell, and K. W. Thomas, 1998: An enhanced hail detection algorithm for the WSR-88D. Wea. Forecasting, 13, 286-303, Crossref. 